\title{
Clients' perceptions of the quality of post-abortion care in eight health facilities in Dakar, Senegal
}

\author{
Colin Baynes $^{1 \star(1)}$, Mohamed Diadhiou ${ }^{2}$, Grace Lusiola ${ }^{3}$, Kate O’Connell ${ }^{1}$ and Thierno Dieng ${ }^{2}$ \\ ${ }^{1}$ EngenderHealth, Washington, DC, USA, ${ }^{2}$ Le Centre de Formation, Recherche et de Plaidoyer en Santé de la Reproduction \\ (CEFOREP), Dakar, Senegal and ${ }^{3}$ EngenderHealth, Dar es Salaam, Tanzania \\ *Corresponding author. Email: colin.baynes@gmail.com.
}

(Received 28 December 2020; revised 3 June 2021; accepted 3 June 2021; first published online 30 July 2021)

\begin{abstract}
Post-abortion care (PAC) integrates elements that are vital for women's survival after abortion complications and their ability to meet their subsequent fertility intentions. Currently, the utilization of PAC among women in need remains too low, particularly in settings where unsafe abortion is an appreciable cause of maternal mortality. Interventions have aimed at addressing unmet need; however, these still require information on the extent to which women value different aspects of PAC. This paper presents such evidence from Dakar, Senegal. Exit interviews with 729 PAC clients in 2018 at eight health facilities obtained information on patient characteristics, content of services received and women's perceptions of the quality of care, both overall and according to subject-specific domains. These domains reflect aspects of PAC that are relevant to clients' satisfaction: accessibility, facility environment, information and counselling, family planning, provider technical competence and readiness and client-staff interaction. Ordinal logistic regression models were estimated to identify factors that were associated with women's rating of overall quality of care (on a scale of 1 to 5, 1 being lowest). Predictors that were significantly associated with the outcome were used in a multivariate ordinal logistic regression model that estimated the probability of positive differences in the outcome associated with women's classification of each predictor. Women reported a mean rating of 3.7 for overall quality of care. The lowest domain-specific rating was for quality of information and counselling (mean=2.4) and the highest was for client-staff interaction (mean=3.8). Factors associated with clients' higher odds of being more satisfied with PAC were: physical comfort during the procedure, recall of counselling on treatment procedure, privacy, perceived availability of supplies and medicines, facility admission process, facility cleanliness, waiting time, clarity of counselling and access to different contraceptive methods. Interventions that target these factors may improve the utilization of PAC in Dakar, Senegal.
\end{abstract}

Keywords: Post-abortion care; Senegal; Client satisfaction

\section{Introduction}

In the 1990s, Senegal emerged as a regional leader in maternal health in part because of the government's commitment to expanding access to life-saving treatment for abortion complications, i.e. post-abortion care (PAC) (Dieng et al., 2008). Post-abortion care is a service package that integrates emergency treatment of abortion complications, family planning counselling and, if desired, access to contraceptive methods (Turner \& Corbett, 2003). Post-abortion care was included in the 1994 Program of Action of the International Conference on Population and Development (ICPD), which identified the right to the enjoyment of the highest attainable standard of physical and mental health, including reproductive health (Measham \& Haberland, 2002). 
Since then, governments have scaled up PAC throughout health systems across low- and middle income countries (LMIC), including those, such as Senegal, where the law prohibits induced abortion unless the continuation of the pregnancy endangers the mother's life. In these settings, PAC offers a 'harm reduction' approach to the public health problem of unsafe abortion and unmet need for contraception (Erdman, 2012). Although it is difficult to statistically isolate the contribution of PAC to maternal mortality reduction, it yields alternative evidence of public health impact, including increased contraceptive uptake following treatment and better access to care, especially in rural settings, due to task-shifting of PAC from physicians to mid-level providers (Bullough et al., 2005; Huber et al., 2016).

In 1997, the Ministry of Health (MOH) of Senegal introduced PAC in collaboration with international non-governmental organizations (NGOs), the United Nations Population Fund (UNFPA) and the United States Agency for International Development (USAID) (Thiam et al., 2006). To guide this process, the $\mathrm{MOH}$ commissioned a series of research projects that demonstrated that PAC could be decentralized from tertiary hospitals in large regional capital cities to secondary hospitals and health centres (CEFOREP, 1998). The first wave of studies showed that midwives could effectively use manual vacuum aspiration (MVA) to treat abortion complications in intermediate and primary care settings, and that this led to increases in women's utilization of $\mathrm{PAC}$ and reductions in providers' recourse to riskier, more expensive and painful treatment alternatives (Suh, 2020). Subsequent research demonstrated the use of medical techniques for treating complications through providers and the self-administration of the uterotonic drug misoprostol (Gaye et al., 2014). The MOH has since called for the availability of both surgical aspiration and medical alternatives to PAC provision at all levels of care throughout the Senegalese public health system, garnering praise as a West African success story for the global PAC model and the ICFP reproductive rights agenda (Diadhiou et al., 2008; Suh, 2018).

Despite these successes, data from the previous decade raise concerns. In 2014, only $20 \%$ of married women and $25 \%$ of sexually active unmarried women in Senegal were using modern contraception (Guttmacher Institute, 2015). During this period, some 31\% of pregnancies in the country were unintended and, on average, Senegalese women gave birth to two more children than they desired. It is estimated that $24 \%$ of all unintended pregnancies in the country end in induced abortions, 60\% in unplanned births and 16\% in miscarriages (Sedgh et al., 2015). Furthermore, the Guttmacher Institute reported that, in 2012, the induced abortion rate (an annual incidence measure) was 17 out of every 1000 women of reproductive age in Senegal, and 21 per 1000 in the capital city, Dakar, of which two-thirds were carried out by untrained individuals, including women themselves, and virtually all are clandestine and unsafe (Sedgh et al., 2015). These conditions place women at a disproportionately high risk of experiencing life-threatening complications from abortion. Whereas the abortion complication rate, in 2012, stood at 5.5 complications treated per 1000 women of reproductive age, access to treatment was uneven, with only half of poor women with complications receiving PAC (Guttmacher Institute, 2015).

The World Health Organization (WHO) recommends the use of special studies to learn about clients' perspectives as part of routine monitoring and evaluation of abortion and PAC (World Health Organization, 2003, 2012). Although clients' views have been widely studied in family planning care, there has been considerably less research on women's experiences with PAC (RamaRao \& Mohanam, 2003). Yet, such knowledge is inherently valuable to inform the design of interventions aimed at improving access to this under-utilized and life-saving care (Donnelly et al., 2019). For example, evidence from India and Tanzania illustrates how low acceptability of abortion-related care has led women to seek care from untrained providers or to resort to unsafe self-care practices, thereby jeopardizing the long-term objectives of reducing abortion-related morbidity and mortality (Ganatra \& Elul, 2003; Baynes et al., 2019). Quality of care affects clients' ability and willingness to return to care and utilize post-abortion family planning. Studies of quality improvement in PAC have found that interventions to improve providers' contraceptive 
counselling can result in increases in women's voluntary uptake of post-abortion contraception and reduce repeat abortion (Curtis et al., 2005).

Past research has found that clients' satisfaction with abortion-related care is associated with the interpersonal treatment by staff and the information provided, as well as the individual-level socio-demographic characteristics of clients (Graff \& Tabbutt-Henry, 2003; Deitch et al., 2019). Studies have also shown that components and processes of care shape clients' satisfaction with care received, such as procedure type, facility type, intensity of pain felt during treatment and client choice of treatment method (Becker et al., 2011; Diaz-Olavarrieta, et al., 2012; Maternowska et al., 2015; Grossman, et al., 2019). Additional research has highlighted the relevance of other domains of quality of care to women's evaluation of quality, such as the accessibility of services, the facility environment, integration of family planning counselling and method provision and women's perception of provider's technical competence (Becker et al., 2011; DiazOlavarrieta, et al., 2012).

This study aimed to sustain the tradition of research in Senegal aimed at guiding public sector strategy on improving the accessibility and quality of PAC. It sought to learn about client perspectives regarding the quality of PAC and their satisfaction with care received and focused on urban hospitals in Dakar region, where abortion rates are the highest in the country. It hypothesized that women's satisfaction with PAC received would be a function of the factors emanating from multiple domains of quality of care, socio-demographic factors and aspects of the treatment package they receive.

\section{Methods}

\section{Study environment and context}

The study team was comprised of researchers from the international sexual and reproductive health NGO, EngenderHealth and from Le Centre Régional de Formation, de Recherche et de Plaidoyer en Santé de la Reproduction (CEFOREP) - a Senegalese reproductive health training, research and advocacy NGO - and investigators from the $\mathrm{MOH}$ Directorate of Maternal and Child Health Services. This study served as the baseline evaluation to guide the development of quality improvement and system strengthening interventions aimed at improving PAC, which would be carried out by health care workers and staff of supported facilities that received training and mentorship from EngenderHealth and CEFOREP.

Research was conducted in eight public sector sites offering PAC located in Dakar, and in the neighbouring towns of Pikine, Guédiawaye, Keur Massar and Rufisque. Sites were chosen to reflect the three types of public sector facilities where PAC was available, considering information on the volume of PAC clients admitted to each facility during the previous 12 months. Excluded from consideration in the study were facilities that could not report a minimum of eight PAC clients per month. These criteria affected our ability to select primary care sites ('health posts'). Site selection also took into account $\mathrm{MOH}$ and district health authorities' view on where technical assistance was most needed and could achieve maximum impact on PAC clients. The sites selected were four tertiary hospitals (Hôpital Abass Ndao, Hôpital Roi Baudouin, Hôpital National de Pikine and Hôpital Youssou Mbargane), three intermediate-level health centres (Centre de Santé [CS] Gaspard Kamara, CS Nabil Choucair and CS Keur Massar) and one health post (Poste de Santé [PS] Nimzath). Among the hospitals, the mean number of PAC clients received in the past 12 months was, on average, 32 per month, while among the health centres and health post it was 22 and 19, respectively.

All the recruitment sites offered both surgical and medication PAC procedures. Surgical procedures are typically performed with MVA, and less often with electric vacuum aspiration (EVA). Relatively few procedures are performed with dilation and curettage, which has been recommended for removal from routine PAC protocols (World Health Organization, 2012, 2015). 
Medical techniques involved a health care provider giving women two $200 \mu \mathrm{g}$ pills of misoprostol, which they hold under their tongues for 30 minutes and then swallow the remaining tablet fragments. Women typically remain at the facility, where they receive misoprostol for up to 2 hours for observation and are discharged at the provider's discretion, with analgesics as needed. The type of procedure women receive is typically based on their gestational age, which is either reported or, when possible, determined through ultrasound. According to the Senegalese policy, the $\mathrm{MOH}$ generally offers women under 12 weeks gestation both treatment alternatives - surgical and medical - with the former prioritized for women under 9 weeks gestation because it is more efficient and less costly, requiring less staff time and physical space. Women are eligible for all types of short-acting contraceptive methods, e.g. oral contraceptive pills, injectable methods, condoms, immediately. As well, women can receive hormonal implants immediately following PAC, as well as intra-uterine devices as soon as complete uterine evacuation is confirmed.

\section{Sample size}

The study reported in this article was the baseline component of a pre-post evaluation of a PAC quality improvement intervention that would compare changes in the quality of PAC and uptake of post-abortion contraception experienced in facilities assigned to a treatment and comparison study arm. The overall sampling strategy was to determine the number of clients required for participation in each study arm at baseline and endline in order to detect an expected difference of 15 percentage points in the difference in the proportion of PAC clients that accepted postabortion contraception in the baseline and endline surveys in each arm with $80 \%$ power. For the present analysis, the baseline survey sample was used to calculate the level of difference between women's overall rating of the quality of PAC that could be detected comparing participants enrolled at hospitals $(n=384)$ and at lower-level facilities, i.e. health centres and the health post $(n=345)$ with $80 \%$ power. For the purpose of power calculations, the level of difference in perceived quality of PAC between both groups, as their mean ratings as a proportion of the highest rating possible in each group, was considered. With this, it was determined that the baseline sample size was sufficient to detect a $12 \%$ difference in participants' overall rating of the quality of PAC.

\section{Study procedures}

The study was conducted with a sample of 729 women who received PAC at the study sites between June and September 2018. Women were eligible to participate in the study if they were aged 14 or older and were seeking care for complications in the first trimester of pregnancy. Participants were not screened for the cause of their abortion complications and, therefore, it was assumed that some obtained abortions clandestinely, and unsafely, whereas others had experienced miscarriages. All data collection took place while women were at the sites for their initial PAC visit - not during follow-up appointments. The PAC providers, who had been oriented to the study instrument and procedures, screened clients for further eligibility criteria - namely, that their physical and emotional health status following the procedure was conducive to comprehension of study details that would be imparted during the informed consent process and that they could withstand participation in a 30-45 minute interview. Those deemed eligible were then introduced to female interviewers, who were responsible for recruiting participants.

Interviewers remained on-site at study facilities during routine operating times. Interviewers met with eligible PAC clients who had expressed a willingness to participate in the study during screening in a private room within each facility. There, the interviewers rendered all eligible clients an informed consent process that explained the rationale for the research, steps of research participation, potential risks and benefits of participation, the measures the study would undertake to ensure their privacy and confidentiality, how the information would be used and participants' 
right to withdraw from the study and additional information at any time. Afterwards, women who agreed to participate signed or provided a thumbprint on an informed consent form, which was signed by a staff member of the facility who also served as a witness. Participants were given a copy of the consent form, which included contact information of the study staff. The exit interview survey took between 30 and 45 minutes to complete. All steps, from screening through informed consent and questionnaire administration, were conducted in either Wolof or French, depending on the clients' preference. Informed consent documents were available in both languages.

Data collection was through a six-part questionnaire comprised of closed-answer questions on the following topics: clients' socio-demographic background, reproductive health and family planning experiences, recognition of complications and care-seeking, recall of the elements of care received during PAC, out-of-pocket expenditure on PAC and their perceptions of the quality of care received. The interviewers were graduates of undergraduate programmes in public health, medicine, psychology and/or sociology. Interviewers were trained for one week, after which they carried out a pre-test using the original version of the study questionnaire in electronic format using tablets programmed with Open Data Kit (ODK) software - a free, open-source suite of tools that allows data collection using Android mobile devices and data submission to an online server, even without an internet connection or mobile carrier service at the time of data collection. After 2 days of pre-testing, the data collectors and study team reconvened to finalize the survey and software programming based on experiences recorded during the pilot. Survey data collected through tablets were uploaded daily by data collectors into a central server managed by the research team at CEFOREP, who monitored data completeness and quality on a daily basis during the study. Once data collection was complete, data were cleaned in the ODK database and then transposed into CSV files that were read into $\mathrm{R}$ software version 4.0.2 for analysis.

\section{Study measures and analysis}

The outcome variable measured participants' overall evaluation of the PAC they had received. It was based on a survey item that used numeric anchor points to guide women to rate, on an interval scale, the number they would use to rate the care and treatment they had received at the health facility from which they had just been discharged. During analysis, responses were coded into a five-category ordinal measure in which 1 was lowest and 5 was highest.

The independent variables included measures of women's socio-demographic characteristics, characteristics of their PAC visit (i.e. recall of the counselling they received, treatment procedure and receipt of additional services) and measures of women's perceptions of quality of care. The latter set of measures represent six domains widely considered as salient to the overall quality of PAC: (1) accessibility, (2) the facility environment, (3) information and counselling, (4) integration of family planning services, (5) client interactions with facility staff, including the provider, and (6) providers' technical competency and preparedness to perform PAC. Responses related to women's socio-demographic background were either continuous (e.g. age, parity, gestational age) or categorical (e.g. marital status, level of education and whether they had any children). Measures of PAC visit characteristics included continuous variables (e.g. amount of out-of-pocket expenditure, length of stay in the facility and waiting time) and categorical variables (e.g. evacuation procedure received, intensity of the pain felt during the procedure, recall of counselling on evacuation procedure, post-abortion fertility and contraception and receipt of a contraceptive method). Some of the variables that were originally continuous were placed in ordered categories (e.g. waiting time at facility before receiving care) for convenience. To obtain women's perceptions of different dimensions of quality of care, the survey incorporated fifteen questions, each of which fell under the above-mentioned domains and called upon participants to rank specific aspects of the care they received using the same five-category numerically anchored survey item that was also used to ascertain their ranking of the overall quality of care. Each of these questions was coded into a five-category ordinal measure in which 1 was lowest and 5 was highest. 
Survey data were transferred to the statistical software R, version 4.0.2, for analysis. First, a descriptive analysis was conducted, which estimated proportions and means for the indicators on clients' socio-demographic characteristics, aspects of their PAC visits and measures of perceived quality that fell under the six quality care domains (see Tables 1 and 2). Subsequently, bivariate ordinal logistic regression models were used to determine associations between the three categories of independent variables (client socio-demographic characteristics, PAC visit characteristics and perceptions of specific aspects of quality of care) and the outcome variable on women's overall evaluation of the quality of the PAC they received. The final step of analysis was the fitting of a multivariate ordinal logistic regression model that included all variables from the series of bivariate tests that were statistically significant at $\alpha=0.1$ level. For this step, the polr command from the MASS package in $\mathrm{R}$ was employed, including specification the Hess=true command to estimate a model that returned the observed information matrix (called Hessian) which, in turn, enabled obtaining standard errors and probability values for parameter estimates. The multivariate model was assessed for multi-collinearity between variables by estimating a condition index that provided the variance proportions between all independent variables, which identified sets of variables that had linear associations. Variables were removed if they had a correlation coefficient with another predictor that was greater than 0.5 . Variables that were significant in bivariate tests that were removed for this reason were: (1) receiving pain relief medication, because it was collinear with clients' reporting perception of comfort felt during the procedure; (2) the amount of out-of-pocket expenditure incurred on PAC because it was collinear with clients' perception of the affordability of PAC; (3) whether or not clients received a contraceptive method during PAC because it was collinear with their perception of the accessibility and choice of post-abortion contraceptive methods. For the final analysis, a $p$-value of less than 0.05 was considered as statistically significant. To confirm the findings, in the final model the Brant test was conducted to assess whether the assumption of proportional odds was valid (Brant, 1990).

\section{Results}

\section{Descriptive findings}

The socio-demographic characteristics of the participants are presented in Table 1. Of note, $34 \%$ of participants had never had a live birth before receiving PAC on the date of data collection $(n=250)$. Ninety-five per cent were married or in a union $(n=692), 38 \%$ had completed primary school $(n=280)$ and $47 \%$ had used a modern contraceptive method at least once in the past $(n=345)$.

Fifty-three per cent of participants received PAC at a hospital $(n=384)$, and a more sizeable majority reported that they did not have to wait to receive PAC after admission $(n=490)$. Approximately $60 \%$ of participants were treated with MVA or EVA $(n=432)$ and $22 \%$ received misoprostol $(n=158)$. Thirty-eight per cent of participants were admitted for more than one day.

Although $23 \%$ and $24 \%$ of participants, respectively, reported that they had been counselled on different treatment procedures $(n=167)$ and received information on the steps of the evacuation procedure and what to expect $(n=175)$, only $2 \%$ reported that they had chosen the evacuation procedure they received $(n=15)$. One-third of participants recalled that they received pain relief mediation $(n=241)$, and $49 \%$ recalled experiencing intense $(n=225)$ or unbearable $(n=130)$ pain during the procedure. Thirty-six per cent recalled having received counselling on measures they should undertake at home to ensure recovery $(n=266)$. Although only $38 \%$ of women recalled receiving information on when they could become fertile again after PAC $(n=277), 81 \%$ recalled discussing family planning and contraceptive methods with their PAC provider $(n=587)$. Fortysix per cent of participants were discharged with a modern contraceptive method $(n=338)$, of which the vast majority received a short-acting contraceptive $(n=300)$. 
Table 1. Selected socio-demographic and PAC visit characteristics of clients surveyed $(N=729)$

\begin{tabular}{|c|c|c|}
\hline Variable & No. respondents & $\begin{array}{c}\text { Mean value } \\
\text { (range) }\end{array}$ \\
\hline \multicolumn{3}{|l|}{ Client characteristics } \\
\hline Age (years) & & $28.9(14,48)$ \\
\hline \multicolumn{3}{|l|}{ Parity } \\
\hline 0 & 250 & \\
\hline 1 & 169 & \\
\hline 2 & 115 & \\
\hline 3 & 79 & \\
\hline 4 & 58 & \\
\hline 5 & 34 & \\
\hline 6 & 9 & \\
\hline 7 & 10 & \\
\hline 8 & 3 & \\
\hline 9 & 2 & \\
\hline \multicolumn{3}{|l|}{ Marital status } \\
\hline Married/in union & 692 & \\
\hline Not married/in union & 37 & \\
\hline \multicolumn{3}{|l|}{ Educational attainment } \\
\hline Completed primary school & 280 & \\
\hline Did not complete primary school & 449 & \\
\hline Gestational age at time of abortion ${ }^{a}$ & & $9.4(0,14.5)$ \\
\hline Days since abortion/miscarriage & & $5.6(1,22)$ \\
\hline \multicolumn{3}{|l|}{ Previous abortion reported } \\
\hline Yes & 63 & \\
\hline No & 666 & \\
\hline \multicolumn{3}{|l|}{ Used contraception before } \\
\hline Yes & 345 & \\
\hline No & 384 & \\
\hline \multicolumn{3}{|l|}{ PAC characteristics } \\
\hline \multicolumn{3}{|l|}{ Facility type } \\
\hline Hospital & 384 & \\
\hline Health centre & 345 & \\
\hline \multicolumn{3}{|l|}{ Waiting time $e^{b}$} \\
\hline No wait & 490 & \\
\hline$<30$ minutes & 117 & \\
\hline $30-60$ minutes & 60 & \\
\hline
\end{tabular}


Table 1. (Continued)

\begin{tabular}{|c|c|c|}
\hline Variable & No. respondents & $\begin{array}{c}\text { Mean value } \\
\text { (range) }\end{array}$ \\
\hline $60-120$ minutes & 25 & \\
\hline$>120$ minutes & 34 & \\
\hline \multicolumn{3}{|l|}{ Treatment method } \\
\hline Vacuum aspiration (manual or electric) & 432 & \\
\hline Misoprostol & 158 & \\
\hline Other (e.g. curettage) & 79 & \\
\hline \multicolumn{3}{|l|}{ Length of stayc } \\
\hline Half a day & 280 & \\
\hline Full day & 139 & \\
\hline Overnight & 128 & \\
\hline 2 days & 90 & \\
\hline 3 days & 28 & \\
\hline$>3$ days & 23 & \\
\hline \multicolumn{3}{|l|}{ Out-of-pocket expenditure on PAC (FCFA) } \\
\hline$<27,755$ (1 $1^{\text {st }}$ quartile) & 183 & \\
\hline $27,755-48,923$ ( $2^{\text {nd }}$ quartile) & 231 & \\
\hline $48.923-64,406$ (3rd quartile) & 133 & \\
\hline$>64,406$ ( $4^{\text {th }}$ quartile) & 182 & \\
\hline \multicolumn{3}{|l|}{ No. payments for PAC } \\
\hline$\leq 1$ & 347 & \\
\hline 2 & 184 & \\
\hline 3 & 136 & \\
\hline$\geq 4$ & 62 & \\
\hline \multicolumn{3}{|l|}{ Perceived affordability of PAC } \\
\hline Affordable & 200 & \\
\hline Moderately expensive & 235 & \\
\hline Very expensive & 260 & \\
\hline
\end{tabular}

Table 2 presents the findings on participants' evaluation of the quality of PAC, overall and for particular dimensions of care. Participants' mean overall rating of PAC (on a scale of 1 to 5) was 3.7, with a standard deviation of 0.91. Fifty-three per cent reported that the treatment they received from staff at the facility where they received PAC was either excellent or good $(n=390)$, and 54\% believed that the treatment they received from their PAC provider was excellent or good $(n=395)$. In contrast, $42 \%$ reported that they felt that the clarity of explanations and counselling was excellent or good $(n=309)$. Regarding post-abortion family planning, $32 \%$ and $29 \%$, respectively, reported that counselling and the provision of contraceptive methods were excellent or good $(n=231)$ and that their access to a variety of methods was excellent or good $(n=210)$. 
Table 2. Percentage distribution for clients' ratings of quality of care overall and for specific domains

\begin{tabular}{|c|c|c|c|c|c|c|}
\hline \multirow[b]{2}{*}{ Variable } & \multicolumn{5}{|c|}{$\begin{array}{c}\text { Number of respondents rating the } \\
\text { variable }\end{array}$} & \multirow[b]{2}{*}{$\begin{array}{l}\text { Number } \\
\text { missing }\end{array}$} \\
\hline & Excellent & Good & Acceptable & Poor & $\begin{array}{l}\text { Very } \\
\text { poor }\end{array}$ & \\
\hline \multicolumn{7}{|l|}{ Accessibility } \\
\hline Admission and triage & 177 & 246 & 222 & 45 & 3 & 36 \\
\hline Waiting time after admission & 172 & 207 & 232 & 61 & 21 & 36 \\
\hline \multicolumn{7}{|l|}{ Facility environment } \\
\hline Cleanliness & 147 & 189 & 246 & 82 & 29 & 36 \\
\hline Privacy of service delivery & 143 & 172 & 313 & 61 & 10 & 30 \\
\hline Comfort felt while in care & 159 & 171 & 285 & 66 & 18 & 30 \\
\hline \multicolumn{7}{|l|}{ Information and counselling } \\
\hline $\begin{array}{l}\text { Clarity of explanations and counselling from } \\
\text { PAC provider }\end{array}$ & 109 & 200 & 234 & 80 & 76 & 30 \\
\hline $\begin{array}{l}\text { Amount and type of information on evacuation method } \\
\text { shared by provider }\end{array}$ & 29 & 123 & 136 & 52 & 359 & 30 \\
\hline Advice about how to recuperate at home & 19 & 105 & 182 & 58 & 358 & 30 \\
\hline $\begin{array}{l}\text { Advice provided about when to return to facility (checkup } \\
\text { or for complications) }\end{array}$ & 9 & 108 & 175 & 45 & 362 & 30 \\
\hline \multicolumn{7}{|l|}{ Postabortion family planning } \\
\hline Family planning counselling and services & 70 & 161 & 236 & 95 & 137 & 30 \\
\hline Access to and choice of contraception & 69 & 141 & 206 & 86 & 197 & 30 \\
\hline \multicolumn{7}{|l|}{ Providers' technical competency and preparedness } \\
\hline Comfort felt during procedure & 172 & 194 & 258 & 60 & 15 & 30 \\
\hline Availability of medicines, supplies and equipment. & 180 & 213 & 244 & 50 & 12 & 30 \\
\hline \multicolumn{7}{|l|}{ Client-staff interaction } \\
\hline Treatment received from facility staff & 176 & 214 & 241 & 44 & 3 & 51 \\
\hline Treatment received from PAC provider & 188 & 207 & 252 & 44 & 8 & 30 \\
\hline Overall quality of care & 135 & 251 & 258 & 45 & 10 & 30 \\
\hline
\end{tabular}

With respect to access to care, $38 \%$ reported that their wait time in between admission and receipt of care was excellent or good $(n=279)$, and $27 \%$ felt that the cost of obtaining PAC was financially affordable $(n=200)$. Half of participants felt that the level of comfort they experienced during the evacuation procedure was either excellent or good $(n=366)$, and $54 \%$ reported that they believed that readiness in terms of the availability of essential medicines, supplies and equipment was excellent or good $(n=393)$. Finally, $46 \%$ of women reported that the cleanliness of the facility environment was excellent or good $(n=336)$, and $43 \%$ believed that the level of privacy they had while awaiting and receiving PAC at the facility was excellent or good $(n=315)$.

\section{Factors association with participants' overall evaluation of PAC}

The bivariate analysis found that variables from all domains of perceived quality of care were significantly associated with women's overall evaluation of the quality of the PAC. Fewer variables 
on participants' socio-demographic characteristics were statistically significantly associated with their overall satisfaction: whether women were nulliparous, had completed primary schooling and their gestational age at the time of pregnancy termination. The majority of measures obtained on the content of services received during PAC were significantly associated with women's overall evaluation of quality of care. These included the amount of time they waited for PAC, whether women received medical evacuation, their out-of-pocket expenditure, their perception of the affordability of PAC, whether they received pain relief medication, their recall of counselling on the evacuation procedure, how to recuperate and post-abortion family planning, whether they received contraception and the number of payments they made.

The results of the multivariate ordinal logistic regression model are presented in Table 3 . The two lowest categories of the ordered outcome (participant perceived the overall service quality as 'poor' or 'very poor') were combined into a single category 'poor'. This made it easier to interpret the outcome of the ratio of the odds of a high ranking of overall quality of PAC (i.e. excellent, good or acceptable) and low ranking (i.e. 'poor') for a single unit difference in each predictor. Women who had completed primary schooling were, on average, less likely to rate highly the overall quality of care received (i.e. excellent, good or acceptable versus poor) $(\mathrm{OR}=0.65,95 \% \mathrm{CI}$ : $0.42-0.98$, $p<0.05)$ compared with those who had not completed primary schooling. In other words, compared with women who had not completed primary school, those who had were $35 \%$ less likely to rate the quality of PAC as 'acceptable', 'good' or 'excellent' versus 'poor'. Conversely, women who could recall receiving counselling on treatment procedure alternatives and the steps involved in the chosen procedure were more likely to rate highly the overall quality of care they received $(\mathrm{OR}=2.83$, 95\% CI: $1.60-5.03, p<0.001)$. Regarding women's perceptions of the accessibility of $\mathrm{PAC}$, women who rated the quality of admission and triage procedures highly were more likely to rate highly the overall quality of care received. Compared with women who rated the quality of admission and triage processes one interval point lower (e.g. comparing women who rated admission and triage processes as 'excellent' with women who rated it as 'good', or comparing women who rated it as 'good' with those who rated it as 'acceptable', etc.), those who rated it one interval point higher (e.g. 'excellent' versus 'good', or 'good' versus 'acceptable') were, on average, 1.66 times more likely to give a high rating (i.e. 'acceptable', 'good' or 'excellent' versus 'poor') for the overall quality of PAC $(\mathrm{OR}=1.66,95 \% \mathrm{CI}: 1.13-2.43, p<0.05)$. Similarly, compared with women who waited for 30 minutes or less after admission to receive PAC, those who waited for longer were, on average 0.63 times less likely to rate highly the overall quality of care $(\mathrm{OR}=0.63,95 \% \mathrm{CI}: 0.42-0.97, p<0.05)$. With respect to facility environment, participants who rated the cleanliness of the facility highly were, on average, more likely to provide a high rating of the overall quality of care $(\mathrm{OR}=1.53,95 \% \mathrm{CI}$ : $1.16-2.03, p<0.05)$. Similarly, participants who rated the level of privacy highly were also more likely, on average, to offer a high rating for the study outcome (OR=2.12, 95\% CI: $1.52-2.96, p<0.05)$.

Women who provided a relatively high rating for clarity of information and counselling received from PAC providers were, on average, $27 \%$ more likely to rate highly the overall quality of care $(\mathrm{OR}=1.27,95 \% \mathrm{CI}: 1.02-1.58, p<0.05)$. Although women's recall of counselling on postabortion family planning and fertility was not statistically significantly associated with their rating of overall quality of care, women's perception of their access to, and choice of, different contraceptive methods was (Table 3). Indeed, compared with participants who rated the level of access and choice to different methods one interval point lower, those who rated it one point higher were, on average, $21 \%$ more likely to also highly rate the overall quality of $\mathrm{PAC}$ received $\mathrm{OR}=1.21,95 \% \mathrm{CI}$ : $1.02-1.45, p<0.05)$. Concerning women's perception of the competency of their PAC provider and readiness to provide care, women who provided a relatively high rating of the comfort they felt during the procedure were, on average, approximately three times more likely to rate highly the overall quality of care $(\mathrm{OR}=3.01,95 \% \mathrm{CI}: 2.00-4.59, p<0.001)$. Similarly, relative to those who provided a one interval point higher rating of the perceived availability of essential supplies, medicines and equipment, those who provided a one point lower rating were, on average, roughly 
Table 3. Odds ratios from multivariate ordinal logistic regression analysis examining association between overall ratings of PAC quality and domain-specific quality measures, socio-demographic characteristics and PAC visit characteristics $(N=662)$

\begin{tabular}{|c|c|}
\hline Variable & OR $(95 \% \mathrm{Cl})$ \\
\hline \multicolumn{2}{|l|}{ Individual characteristics } \\
\hline Nulliparous & $1.14(0.74,1.75)$ \\
\hline Completed primary school & $0.65(0.42,0.98)^{*}$ \\
\hline Gestational age at time of abortion & $1.05(0.99,1.12)$ \\
\hline \multicolumn{2}{|l|}{ PAC visit characteristics } \\
\hline Type of facility (Ref.: hospital) & $0.79(0.48,1.31)$ \\
\hline Treatment method (misoprostol)(Ref.: not misoprostol) & $1.05(0.63,1.76)$ \\
\hline Treatment method (curettage) & $0.89(0.47,1.68)$ \\
\hline Recall counselling on treatment method and procedure (Ref.: no) & $2.83(1.60,5.03)^{\star \star}$ \\
\hline Recall counselling on how to recuperate after discharge (Ref.: no) & $1.12(0.78,1.59)$ \\
\hline Recall counselling on post-abortion fertility and family planning (Ref.: no) & $1.16(0.74,1.85)$ \\
\hline \multicolumn{2}{|l|}{ Domain-specific quality of care ratings } \\
\hline \multicolumn{2}{|l|}{ Accessibility } \\
\hline Admission and triage (Ref.: poor) & $1.66(1.13,2.43)^{\star}$ \\
\hline Waiting time between admission and receipt of services (Ref.: 30 minutes or less) & $0.63(0.42,0.97)^{\star}$ \\
\hline \multicolumn{2}{|l|}{ Perceived affordability (Ref.: affordable) } \\
\hline Moderately expensive & $0.76(0.46,1.27)$ \\
\hline Very expensive & $0.88(0.53,1.47)$ \\
\hline \multicolumn{2}{|l|}{ Number of payments (Ref.: 1 ) } \\
\hline More than one payment & $0.99(0.64,1.51)$ \\
\hline \multicolumn{2}{|l|}{ Facility environment } \\
\hline Facility cleanliness (Ref.: poor) & $1.53(1.16,2.03)^{*}$ \\
\hline Level of privacy (Ref.: poor) & $2.12(1.52,2.96)^{\star}$ \\
\hline General comfort felt in the facility environment (Ref.: poor) & $1.26(0.90,1.75)$ \\
\hline \multicolumn{2}{|l|}{ Information and counselling } \\
\hline Level of clarity of information and counselling received & $1.27(1.02,1.58)^{\star}$ \\
\hline \multicolumn{2}{|l|}{ Post-abortion family planning } \\
\hline Access and choice regarding contraceptive methods & $1.21(1.02,1.45)^{\star}$ \\
\hline \multicolumn{2}{|l|}{ Technical competence } \\
\hline Comfort felt during the treatment procedure & $3.01(2.00,4.59)^{\star}$ \\
\hline Availability of required supplies, medications and equipment & $2.08(1.45,3.01)^{\star}$ \\
\hline \multicolumn{2}{|l|}{ Client-staff interaction } \\
\hline The way client was treated by facility staff (Ref.: poor) & $1.26(0.82,1.98)$ \\
\hline The way client was treated by PAC provider (Ref.: poor). & $1.21(0.77,1.89)$ \\
\hline
\end{tabular}

${ }^{*} \alpha<0.05 ;{ }^{* *} \alpha<0.001$. 
twice as likely to offer a higher rating of overall quality of care $(\mathrm{OR}=2.08,95 \% \mathrm{CI}$ : $1.45-3.01$, $p<0.001)$. Of the measures incorporated in the multivariate model on client-staff interactions, neither that which rated women's perceptions of the treatment they received from facility staff nor from provider was significantly associated with their overall rating of PAC quality.

The Brant test statistic to assess the assumption of proportional odds was not significant $(p=0.95)$, which indicated that ordinal logistic regression was an appropriate model for the study data.

\section{Discussion}

This study sought to understand how women view the quality of post-abortion care provided at public health facilities in Dakar, Senegal, and the range of factors that contribute to their overall evaluation of the care they received. High percentages of the PAC clients interviewed believed that they were treated well by facility staff and their PAC providers, and that the environment in which they received care was clean and private. These results suggest that the public sector programme is effective at addressing some of clients' needs and priorities. The finding that women offer a relatively high overall rating of the quality of care reinforces this conclusion. Nevertheless, the results illuminate areas where improvements could be made and suggest which might be most valued by PAC clients. Although the proportions of participants enrolled from hospitals and lower-level facilities were approximately equal, the study could only recruit women from one primary-level health post due to low service volume for PAC at this level of care in Dakar during the 12 months that preceded the study. This suggests that the public health system of Dakar may benefit by refocusing some attention on the decentralization of PAC, particular those aspects of the strategy that were successful in the 1990s and 2000s (Dieng et al., 2008). Unlike earlier studies, this one did not find differences in women's overall ratings of care by treatment procedure or by site of care (Sihvo et al., 1998; Rørbye et al., 2005). This lends support to the notion that emphasizing medical treatment for PAC at the primary care level - a decision that may improve efficiency and reduce costs - will not lead to reductions in client satisfaction (Vlassof et al., 2016).

This study identified accessibility as key to client satisfaction and yields a positive sign with regards to one dimension of this - waiting time after admission - which women reported was, usually, low and acceptable. In contrast, concerning the financial aspects of access, the majority of participants reported that PAC was either moderately or very expensive. Indeed, the average out-of-pocket expenditure that women incurred to pay for PAC was FCFA 51,427 (approximately US\$90). This is approximately the equivalent of $7 \%$ of Senegal's 2018 per capita gross domestic product. Although the analysis did not reveal a statistical association between costs or affordability on women's overall rating of PAC quality, it is relevant to highlight this, particularly given that previous studies have shown that the cost of abortion-related care in low-income settings adversely affects women's satisfaction and decisions to utilize abortion complication-related treatment (Ilboudo et al., 2015; Parmar et al., 2017).

Whereas women, on average, rated their care highly with respect to their physical comfort during the treatment procedure and perception of the availability of all essential medicines, supplies and equipment, the descriptive analysis of the features of their PAC visit that women could recall offered a contrasting perspective. Only one-third of women recalled having received pain relief medication and nearly half reported that the procedure was intensely or unbearably painful. A recent study in Tanzania also described dissonance between women's description of discomfort and dissatisfaction with the counselling they received during PAC, and moderately high ratings of their providers' performance (Baynes et al., 2019). A study from Mexico illustrated similar contrasts between quantitative measures of how women classify the care they received and the narratives they offered during in-depth interviews (Díaz-Olavarrieta et al., 2012). This underscores the relevance of qualitative research to the monitoring and evaluation of PAC and efforts aimed at 
making treatment more acceptable to clients (Edwards, 1999; Edwards et al., 2004). Nevertheless, the insight this study gave from clients illuminates opportunities for programme improvements. Although participants rated with moderate praise the clarity of the explanations and counselling that PAC providers actually provided, they concurrently acknowledged the lack of information sharing and advice with respect to specific topics, such as self-care during recovery, post-abortion fertility and contraceptive methods.

In highlighting factors that contribute to women's overall evaluation of quality of care, this analysis found that, after adjustment, women's interaction with facility staff and PAC providers did not meaningfully influence their overall rating for the quality of care. This observation contrasts those proffered by similar studies on abortion and PAC carried out in other high- and lowincome settings, which reported that respectful, non-judgmental treatment from non-clinical staff, nursing assistants and the actual PAC provider, relative to other factors, appreciably shapes women's satisfaction (Elul, 2010; Becker et al., 2011). The study's observation of high ratings of clientstaff interactions, together with relatively poor ratings and recall of counselling elements, point to clear opportunities for facility staff to achieve better client satisfaction. Previous research on PAC suggests that incorporating concerted educational protocols into PAC provision, including use of job aids and informational leaflets to promote post-abortion fertility awareness and contraceptive eligibility, enhance women's satisfaction with the care they received and their likelihood of averting future unintended pregnancies and repeat abortion by timely uptake of family planning after treatment for abortion complications (Savelieva et al., 2003; Huber et al., 2016).

The potential for information, education and communication (IEC) interventions to meet PAC clients' needs is underscored by the association between women's assessment of the clarity of the information and counselling that providers did impart and their overall evaluation of PAC. This corroborates findings reported by previous studies (Stolarsky \& Peshkatari, 2010). Whereas recent research has emphasized the need for strengthened post-abortion family planning counselling, this analysis suggests that women's overall satisfaction with care is more related to whether their provider counsels them on the treatment procedure. That this association was significant after adjustment for women's rating of the comfort they felt during the procedure suggests that receiving counselling on treatment steps and the likely discomfort women will feel during the procedure helps women cope with pain and emotional stress (Grossman et al., 2019).

Similar to other studies, women's perspectives on features of the facility environment were also associated with their assessment of overall quality of care (Zapka et al., 2001). This indicates that future quality improvement efforts should ensure efficient and well-organized reception and triage processes for women admitted with abortion complications, the cleanliness of waiting and treatment areas and privacy. Even though participants in this study were limited in terms of their ability to assess their providers' technical skills, their reports of comfort and pain experienced during the procedure offer insight on this. The factor most appreciably associated with women's overall rating of PAC quality was the level of comfort they felt during the treatment procedure and their recall of counselling information on their procedure. Echoing earlier remarks, this provides strong evidence of the need to ensure competent and transparent handling of clients' pain during the treatment procedure.

An additional aspect of technical competence is the degree to which providers can use appropriate supplies, medicines, commodities and equipment when needed. This analysis underscores the relevance of this from the perspective of clients whose perception of providers' readiness in this sense was significantly associated with their rating of overall PAC quality. Similarly, while women's rating of information and counselling on post-abortion fertility and family planning did not bear out significantly in the adjusted analysis, their perception of access to and choice of a contraceptive method did. This suggests that beyond having a respectful interaction with facility staff, and receiving relevant counselling, women's satisfaction is shaped by their perception of material readiness and access to informed choice about service delivery alternatives. This is consistent with findings from early operational research studies on PAC, which emphasized the 
importance of making a wide range of contraceptive options available to PAC clients in the same setting where treatment takes place (Solo et al., 1999). Given that women in Dakar who suffer first trimester abortion complications have access to two treatment alternatives - surgical or medical the public sector programme should address barriers to availing clients the opportunity to select their treatment procedure, which previous studies indicate may also enhance clients' satisfaction with the care they receive (Kanstrup et al., 2018).

This study has several limitations. Since data collection took place on-site at the facilities where women received PAC, it is possible that social desirability bias affected how they responded to questions in the survey. To address this, interviews were carried out in private, and participants were reassured that their responses would remain utterly confidential. Another limitation is the generalizability of the results. The study was held in eight public sector facilities - four hospitals, three health centres and one health post - in Dakar. The experiences of women who received care at these sites may be different from those who receive care from other facilities, particularly those with lower client volumes, from the private sector and in rural areas. While this study's results are illuminating, future research should also explore the perspectives of PAC providers and facility staff who face constraints to providing high-quality care. This analysis represents best efforts to understand quantitative relationships between the range of factors that shape whether women feel satisfied with their experiences when obtaining PAC and their ultimate perceptions of quality of care; however, qualitative data will also offer crucial insights on this topic and are, therefore, highly advisable for the future.

In conclusion, these findings elucidate factors that underlie suboptimal utilization of PAC in Dakar, where abortion rates are the highest in the country. While not surprising, these opportunities for improvement are crucial to underscore if the system is to attract more PAC clients into care. This study reports that the prospects of this may increase if facility staff and collaborators work towards guaranteeing that PAC is made available more efficiently, privately, as painlessly as possible and in settings that are clean, well-equipped and well-stocked. Importantly to clients, staff delivering PAC should provide clear counselling and choice of treatment options and access to a wide variety of contraceptive methods. Commitment to ensuring that these fundamental aspects of PAC are in place, consistently and ubiquitously across PAC settings, will represent essential progress towards meeting unmet need for PAC in Senegal.

Funding. This work was supported by the United States Agency for International Development (USAID) under Cooperative Agreement AID-OAA-00050.

Conflicts of Interest. The authors report conflicts of interest.

Ethical Approval. Ethical clearance for this study was obtained from the National Ethical Committee for Health Research (CNERS) of Senegal MOH Protocol SEN 17/53) and Western Institutional Review Board in the United States (Protocol No. 20171739).

Data availability. The data from this study are not publically available due to Internal Review Board restrictions and regulations of the Government of Senegal. Study materials are available from the corresponding author upon reasonable request.

\section{References}

Baynes C, Yegon E, Lusiola G, Kahando R, Ngadaya E and Kahwa J (2019) Women's satisfaction with and perceptions of the quality of postabortion care at public-sector facilities in mainland Tanzania and in Zanzibar. Global Health Science and Practice 7, S299-S314.

Becker D, Diaz-Olavarrieta C, Juarez C, Garcia SG, Sanhueza P and Harper CC (2011) Clients' perceptions of the quality of care in Mexico City's public-sector legal abortion program. International Perspectives in Sexual and Reproductive Health 37(4), 191-201.

Brant R (1990) Assessing proportionality in the proportional odds model for ordinal logistic regression. Biometrics 46, 1171-1178. 
Bullough C, Meda N, Makowiecka K, Ronsmans C, Achadi EL and Hussein J (2005) Current strategies for the reduction of maternal mortality. BJOG: An International Journal of Obstetrics and Gynaecology 112(9), 1180-1188.

CEFOREP (1998) Introduction des soins obstétricaux d'urgence et de la planification familiale pour les patients présentant des complications liées à un avortment incomplete. Le Centre Regionale de Formation, Recherche et de Plaidoyer en Santé de la Reproduction (CEFOREP), Dakar, Senegal.

Curtis C, Huber D and Moss-Knight T (2005) Postabortion family planning : addressing the cycle of repeat unintended pregnancy and abortion. International Perspectives in Sexual and Reproductive Health 36(1), 44-48.

Deitch J, Amisi JP, Martinez S, Meyers J, Muselemu JB, Nzau JJ et al. (2019) “They love their patients": client perceptions of quality of postabortion care in North and South Kivu, the Democratic Republic of the Congo. Global Health Science and Practice 7, S285-S298.

Diadhiou M, Dieng T, Diop N, Faye Y, Moreau JC, Thieba B et al. (2008) Les soins après avortement en Afrique de l'Ouest Francophone, 10 ans après: leçons apprises de leur introduction et de leur in- stitutionnalisation. Journal de la societé Africaine de Gynécologues et Obstétriciens 9(2), 38-46.

Díaz-Olavarrieta C, Garcia SG, Arangure A, Cravioto V, Villalobos A, Abisamra R et al. (2012) Women's experiences of and perspectives on abortion at public facilities in Mexico City three years following decriminalization. International Journal of Gynecology and Obstetrics 118, S15-S20.

Dieng T, Diadhiou M, Diop N and Faye Y (2008) Evaluation des progès de l'initiative Africaine Francophone pour les Soins Après Avortement. Dakar, Senegal.

Donnelly KZ, Dehlendorf C, Reed R, Agusti D and Thompson R (2019) Adapting the interpersonal quality in family planning care scale to assess patient perspectives on abortion care Journal of Patient-Reported Outcomes 3(1), http://doi.org/10. 1186/s41687-018-0089-7.

Edwards C (1999) Accessing the user's perspective. Health and Social Care in the Community 8(6), 417-424.

Edwards C, Staniszweska S and Crichton, N (2004) Investigation of the ways in which patients' reports of their satisfaction with healthcare are constructed. Sociology of Health and Illness 26(2), 159-183.

Elul B (2010) Assessments of the importance of provider characteristics for abortion care: data from women in Rajasthan, India. Healthcare for Women International 21(1), 72-95.

Erdman JN (2012) Harm reduction, human rights, and access to information on safer abortion. International Journal of Gynecology and Obstetrics 118(1), 83-86.

Ganatra B and Elul B (2003) Legal but not always safe: three decades of a liberal abortion policy in India. Gaceta Medica de Mexico 139 (Supplement 1), S103-108.

Gaye A, Diop A, Shochet T and Winikoff B (2014) Decentralizing postabortion care in Senegal with misoprostol for incomplete abortion. International Journal of Gynecology and Obstetrics 126, 223-226.

Graff K and Tabbutt-Henry J (2003) Client-provider communication in postabortion care. International Journal of Gynecology and Obstetrics 29(3), 126-129.

Grossman D, Raifman S, Bessenaar T, Duong LD, Tamang A and Dragoman MV (2019) Experiences with pain of early medical abortion: qualitative results from Nepal, South Africa, and Vietnam. BMC Women's Health 19(1), http://doi.org/ 10.1186/s12905-019-0816-0

Guttmacher Institute (2015) Abortion in Senegal: Fact Sheet. Guttmacher Institute, New York.

Huber D, Curtis C, Irani L, Pappa S and Arrington L (2016) Postabortion care : 20 years of strong evidence on programming components. Global Health Sciences and Practice 4(3), 481-494.

Ilboudo PGC, Greco G, Sundby J and Torsvik G (2015) Costs and consequences of abortions to women and their households : a cross-sectional study in Ouagadougou, Burkina Faso. Health Policy and Planning 30, 500-507.

Kanstrup C, Mäkelä M and Hauskov Graungaard A (2018) Women's reasons for choosing abortion method: a systematic literature review. Scandinavian Journal of Public Health, 46(8), 835-845.

Maternowska MC, Mashu A, Moyo P, Withers M and Chipato T (2015) Perceptions of misoprostol among providers and women seeking post-abortion care in Zimbabwe. Reproductive Health Matters 22(44, S), 16-25.

Measham D and Haberland N (2002) Introduction. In Measham D and Haberland N (eds) Responding to Cairo: Case Studies of Changing Practice in Reproductive Health and Family Planning. Population Council, New York.

Parmar D, Leone T, Coast E, Murray SF, Vwalika B, Parmar D et al. (2017) Cost of abortions in Zambia : a comparison of safe abortion and post abortion care. Global Public Health 12(2), 236-249.

RamaRao S and Mohanam R (2003) The quality of family planning programs: concepts, measurements, interventions, and effects. Studies in Family Planning 34(4), 227-248.

Rørbye C, Nørgaard M and Nilas L (2005) Medical versus surgical abortion: comparing satisfaction and potential confounders in a partly randomized study. Human Reproduction 20(3), 834-838.

Savelieva I, Pile JM, Sacci I and Loganathan R (2003) Postabortion Family Planning Operations Research Study in Perm, Russia Postabortion Family Planning Operations Research Study in Perm, Russia. United States Agency for International Development, Washington, DC. URL http://www.researchgate.net/publication/268376314 (accessed 10th December 2020).

Sedgh G, Hassane Sylla A, Philbin J, Keogh S and Ndiaye S (2015) Estimates of the incidence of induced abortion and consequences of unsafe abortion in Senegal. International Perspectives on Sexual and Reproductive Health 41(1), 11-19. 
Sihvo S, Hemminki E, Kosunen E and Koponen P (1998) Quality of care in abortion services in Finland. Acta Obstetricia et Gynecologica Scandinavica 77(2), 210-217.

Solo J, Billings DL, Aloo-Obunga C, Ominde A and Makumi M (1999) Creating linkages between incomplete abortion treatment and family planning services in Kenya. Studies in Family Planning 30(1), 17-27.

Stolarsky G and Peshkatari ACE (2010) An Evaluation of ACCESS-FP's Work in Albania : Postpartum and Postabortion Family Planning. Jhpiego, an affiliate of Johns Hopkins University, Baltimore. URL: https://www.k4health.org/sites/ default/files/Albania Evaluation Report_6-8-10Final_0.pdf (accessed 10th December 2020).

Suh S (2018) Accounting for abortion: accomplishing transnational reproductive governance through post-abortion care in Senegal. Global Public Health 13(6), 662-679.

Suh S (2020) What post-abortion care indicators don't measure: global abortion politics and obstetric practice in Senegal. Social Science \& Medicine 254, 112248

Thiam FT, Suh S and Philippe M (2006) Scaling Up Postabortion Care Services: Results from Senegal. Management Science for Health. Occasional Papers No. 5.

Turner KL and Corbett MR (2003) Essential elements of postabortion care: origins, evolution and future directions. International Family Planning Perspectives 29(3), 106-111.

Vlassoff M, Singh S, Onda T, Lane M and York N (2016) The cost of post-abortion care in developing countries : a comparative analysis of four studies. Health Policy and Planning 31(8), 1020-1030.

World Health Organization (2003) Safe Abortion: Technical and Policy Guidelines for Health Systems. World Health Organization, Geneva.

World Health Organization (2012) Safe Abortion: Technical and Policy Guidance for Health Systems. World Health Organization, Geneva.

World Health Organziation (2015) Health Worker Roles in Providing Safe Abortion Care and Postabortion Contraception. World Health Organization, Geneva.

Zapka JG, Lemon S, Peterson LE, Palmer H and Goldman MB (2001) The silent consumer: women's reports and ratings of abortion services. Medical Care 39(1), 50-60.

Cite this article: Baynes C, Diadhiou M, Lusiola G, O'Connell K, and Dieng T (2022). Clients' perceptions of the quality of post-abortion care in eight health facilities in Dakar, Senegal. Journal of Biosocial Science 54, 760-775. https://doi.org/10.1017/ S0021932021000365 